\title{
The impacts of the antecedents on absorptive capacity and export performance: a meta-analytic review
}

\author{
$W u$ Wann-Yih ${ }^{1}$ and Permatasari Yani ${ }^{2, *}$ \\ ${ }^{1}$ International Business Department, Chinese Culture University, Taipei, Taiwan \\ ${ }^{2}$ Department of Accountancy, Faculty of Economics and Business, Universitas Airlangga, Surabaya, Indonesia
}

\begin{abstract}
Although exporting performance and absorptive capacity, with its relevant antecedents have been studied extensively, rare of them have integrated these variables into a more comprehensive framework. Not only this study aims to synthesize extant knowledge on the subject based on meta-analysis and empirical verify the influences of absorptive capacity on export performance, but also the antecedents of absorptive capacity are evaluated. The assessment reveals that: all hypotheses are supported and the antecedents of absorptive capacity have small-to-medium effects size with positive relationship.

Keywords: Export performance, Absorptive capacity, Meta-analysis
\end{abstract}

\section{Introduction}

As a result from the still fragmented knowledge regarding successful export practice--despite of it has been an important stream of international marketing research for over 25 years--, the importance of theories development in this exporting area is arising. Therefore it is essential to develop theory which focuses on the causal processes that give enlargement to variation in export performance among firms [1,2].

This study proposes three antecedents of absorptive capacity which are regulatory focus, export orientation, and organizational cultural intelligence. This study argues that having promotion focus or prevention focus, being proactive toward customers' needs or being responsive toward competitors' actions in the market, and having ability to adapt will increase the level of absorptive capacity [3-6]. Moreover, this study discusses about under what conditions that these antecedents have stronger or weaker influences toward firms' absorptive capacities in their export activities.

\section{Literature Review}

\subsection{The Effect of Regulatory Focus}

Regulatory focus refers to when a person pursues a goal in a way that maintains the person's own personal values and beliefs, with basic principle that people motivated to approach pleasure but avoid pain [3]. Higgins $(1997,1998)[3,4]$ proposed two distinct self-regulatory systems, one in which people have a promotion focus and the other in which they have a prevention focus. Each regulatory focus influences the nature and magnitude of the people's emotional experience and affects the perception, decision making, and also individuals' behaviors and performances $[3,4,7]$. As for the context of export, exporters with stronger chronic promotion concern tend to be more "risk-taker", wanting to benefit from high energy and to develop the advantage of creative behaviors [7-10]. On the other hand, exporters with stronger chronic prevention focus are more to be "risk-averse" $[8,11]$. Furthermore, the purpose of the prevention focus is wanting to avoid the chance of illness or assure their safety and security, to maintain routines, and to preserve the status quo $[9,10]$. Therefore, these exporters will have intention to form relationships with their partners, produce some innovation, increasing the export performances, and developing its absorptive capacity at the same time. Thus, this study propose:

$H 1$ - There is a positive influence of exporters' regulatory focus on their absorptive capacity

H4 - There is a positive influence of exporters' regulatory focus on (a) organizational innovativeness, (b) export performance, and (c) relationship satisfaction

\subsection{The Effect of Export Orientation}

In this study, export orientation is developed based on the market orientation, which consists of two behavioral components: customer orientation and competitor orientation [5]. Customer orientation emphasizes the role of sufficient

\footnotetext{
* Corresponding author: yanipermatasari@feb.unair.ac.id
} 
understanding of target customers. Consequently, the firm will have greater capacity to absorb new information related with its customers, and also have better export outcomes. On the other hand, some firms frequently makes decisions so as to perform well relative to their competitors which Armstrong and Collopy (1996) [13] refers that as competitor-oriented objectives.

Furthermore, the customer and competitor orientations are two distinct approaches that will lead to competitive advantage. Because customer-oriented exporters has detailed analyses of customer needs in order to reach customer's high satisfaction, a customer orientation will result in a differentiation advantage. For a competitor-oriented exporters, they tends to focus on monitoring the costs in order to match the competitors initiative, thus they may have a cost advantage as a result [14]. Therefore, this study propose,

H2 - There is a positive influence of exporters' export orientation on their absorptive capacity

H5 - There is a positive influence of exporters' export orientation on (a) organizational innovativeness, (b) export performance, and (c) relationship satisfaction

\subsection{The Effect of Cultural Intelligence}

Cultural intelligence (CQ) is defined as a natural ability that an outsider has, to interpret someone's unfamiliar and ambiguous gestures in just the way that person's compatriots and colleagues would, even to mirror them [15]. Ang and Inkpen (2008) [16] stated that there are three components of a firm's CQ that is managerial, competitive, and structural capabilities. They also suggested that as boundary spanners, project managers or exporters should come into daily contact with supplier and/or customer in the international business ventures. Hence, the exporters should have greater level of cultural awareness, knowledge about the other cultures, and the capability to gives appropriate verbal and nonverbal actions with people from different cultures [17].

Moreover, exporters' possession of competitive CQ could be viewed as a meta-capability [18] that transcends technical or operational capabilities. Consequently, exporters who have these competitive CQ can be expected to have better capability to create relationship satisfaction, to have greater absorptive capacity, and good export performance. Thus, this study propose:

H3 - There is a positive influence of exporters'organizational cultural intelligence on their absorptive capacity

H6 - There is a positive influence of exporters' organizational cultural intelligence on (a) organizational innovativeness, (b) export performance, and (c) relationship satisfaction

\subsection{The Effect of Absorptive Capacity}

Absorptive capacity is the ability of a firm to recognize the value of new, external information, assimilate it, and apply it to commercial ends to produce a dynamic organizational capability. Such ability is critical to its innovative capabilities [19-20].

Lane et al. (2001) [21] developed measures for the three processes within absorptive capacity of recognition, assimilation, and utilization (c/f [22]). In the context of export activity, when exporters have ability to recognize, absorb, and understand new external related to the operations knowledge, then apply that new knowledge toward commercial ends right after combining it with their prior knowledge, the exporters can be expected to have more innovations, greater export-related performance, and higher satisfaction with its partners [19,20,23]. Thus, this study proposes: H7 - There is a positive influence of exporters' absorptive capacity on (a) organizational innovativeness, (b) export performance, and (c) relationship satisfaction

\section{Methodology}

\subsection{Conceptual Framework}

In this study, the following conceptual framework, which is developed based on the research backgrounds, describes the relationship between absorptive capacity and its antecedents, and their impact to the product innovativeness, export performance, and relationship satisfaction. 


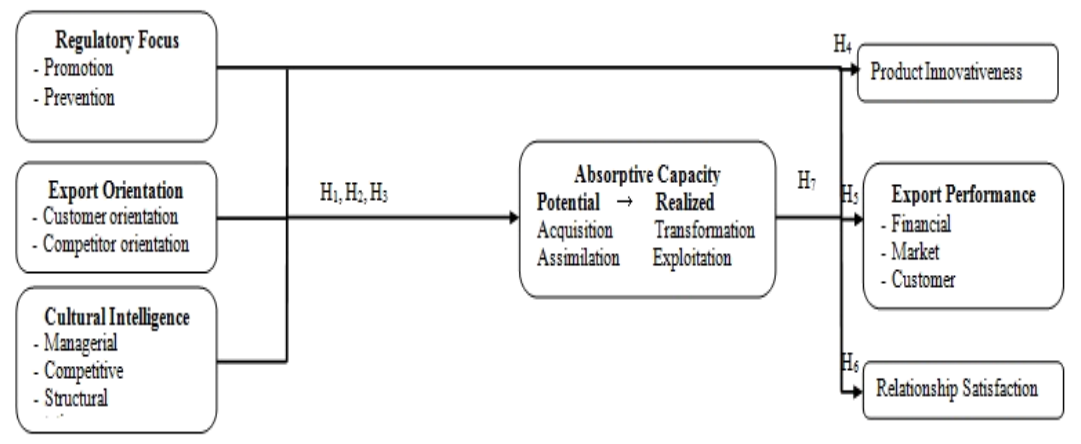

Fig. 1. The Conceptual Framework

\subsection{Construct Measurement}

After completing the journal-by-journal searching process, a total of 84 studies done in 1984-2016 was obtained in this study. Of these 84 studies, there was a body of 18 that included theoretical papers, and qualitative investigations, which left 66 studies with quantitative validation. These studies produced 15,804 independent samples, 66 effect sizes, and a cumulated $n$ of 28 subjects. A list of the studies used in our empirical meta-analysis is available on request.

All identified studies were examined in terms of the following relevant variables: authors, year, journal, total sample size, the statistic measurement of each variable, and effect sizes. Two alternatives are used for inclusion: (1) correlational studies must present the correlation coefficient (r) or the standardized regression (beta) coefficient or (2) studies must present the related statistic (t-test, p-value) for the relationship between related variables. These statistics could be converted into effect size (r) and Fisher Z effect using Comprehensive Meta-Analysis (CMA) Software. In addition, this paper also incorporates those studies that provide only the standardized regression (beta) coefficients using the formula suggested by Peterson and Brown (2005) to estimate the correlations from the beta coefficients. The formula used is $r=0.98 \beta+0.05 \gamma$, where $\lambda$ is a variable that equals 1 when $\beta$ is non-negative and 0 when $\beta$ is negative.

Moreover, this study also conducts homogeneity analysis which tests whether the assumption that all of the effect sizes are estimating the same population mean is a reasonable assumption. Homogeneity of the effect size distribution was tested by the Q statistic, distributed as a chi-square with degree of freedom calculated by $n-1$, where $n$ is a number of studies [24].

\section{Result}

Table 1 presents the result from integration of effect sizes of the variable. Reminds as stated in Lipsey and Wilson (2001) [24] $\mathrm{r}$ analyzing the magnitude of effect sizes ( $\mathrm{r}<0.10$ as small; $r=0.25$ as medium, and $r>0.40$ as large effect size), it is shown in Table 1 that these variable, the antecedents of absorptive capacity have small-to-medium effects size with the relationship varying from 0.018 (Hypothesis 3) to 0.311 (Hypothesis 9). Following is the analysis of the hypotheses result,

Hypothesis 1 shows the coefficient correlation result as 0.279 which shows that there is positive correlation with medium effect size. Different with hypothesis 1 , hypothesis 4 has small effect size with coefficient of correlation $(\mathrm{r})=$ 0.025 .

Hypothesis 2 has the coefficient correlation result as 0.109 . Therefore, this hypothesis is supported with medium correlation. So does Hypothesis 5, with coefficient correlation as 0.224 , this hypothesis is supported with category of medium effect size.

Hypothesis 3 and Hypothesis 6 have coefficient correlation 0.018 and 0.038 , which means there is a small effect size. Finally, the last hypothesis asserted that exporters' absorptive capacity has positive influences on organizational innovativeness, export performance, and relationship satisfaction. This hypothesis is supported because it has coefficient correlation $r=0.309$ with category medium effect size.

\section{Conclusion}

\subsection{Conclusion}

From the findings above, this study can be concluded as follows: First of all, exporters emphasizing on prevention focus - which tend to be "risk-averse", concerned with duties and obligations, are likely to be sensitive to the presence or absence of punishments, and use avoidance as a goal attainment strategy - and exporters emphasizing on promotion 
focus, which is wanting to benefit from high energy and to develop the advantage of creative behaviors [9,10], will have intention to form relationships with their partners, produce some innovation, increase the export performances, and develop its absorptive capacity at the same time. Secondly, it is important for exporters to have customer orientation or competitor orientation simultaneously. These are two distinct approaches that will lead to competitive advantage.

Thirdly, firms that have this competitive capability will be able to integrate and combine various knowledge assets within the firm and between the firm and international business partners [21,22]. Consequently, exporters who have these competitive CQ can be expected to have better capability to create relationship satisfaction, to have greater absorptive capacity, and good export performance.

Fourthly, when exporters have ability to recognize, absorb, and understand new external related to the operations knowledge, then apply that new knowledge toward commercial ends right after combining it with their prior knowledge, the exporters can be expected to have more innovations, greater export-related performance, and higher satisfaction with its partners $[23,24,27]$. Therefore, in order to increase the export performance, exporters could maximizing the using of the antecedents of absorptive capacity.

\subsection{Limitation and Future Research Direction}

There are several limitations in this study. Though the literatures were comprehensively surveyed, it can not guarantee a full coverage of all available studies. In addition, several studies could not be included due to insufficient information. However, no systematic difference between the studies included and those few not included are anticipated. The challenge for future research is to reach beyond studies which are found here to identify other important contextual variables related to the export performance.

\section{References}

1. N.-E. Aaby, S.F. Slater. Intl. Mrktg Rev. 6(4), 53-68 (1989).

2. S. K. Chetty, R.T. Hamilton. Intl. Mrktg Rev, 10(3), 26-34 (1993).

3. E.T. Higgins. Amrcn Psycl., 52, 1280-1300 (1997).

4. E.T. Higgins. Adv. in Exp. Soc. Psycl., 30, 1-46 (1998).

5. J. C. Narver, S. F. Slater. J.of Mrktg, 54(4), 20-35 (1990).

6. S. Ang, A. C. Inkpen. Dec. Sci., 39, 337-358 (2008).

7. J. Brockner, T. E. Higgins. Org. Bhvr. \& Human Dec. Proc., 86, 35-66 (2001).

8. R. Friedman, J. Förster. J. of Prsnlty and Soc. Psycl., 81, 1001-1013 (2001).

9. J. L. Aaker, A. Y. Lee. J. of Consmr. Rsrch., 28, 33-49 (2001).

10. R. Kark, D. Van Dijk. Acdmy. of Man. Rev., 32(2), 500-528 (2007).

11. E. Crowe, E. T. Higgins. Org. Bhvr. \& Human Dec. Proc., 69, 117-132, (1997).

12. A. K. Kohli, B. J. Jaworski. J.of Mrktg, 54(2), 1-18(1990).

13. J. S. Armstrong, F. Collopy. J. of Mrktg Rsrch, 33(2), 188-199(1996).

14. K. Z. Zhou, J. R. Brown, C. S. Dev, S. Agarwal. J. of Intl. Busns. Stud., 38, 30(2007).

15. P. C. Earley, E. Mosakowski. Harvard Business Review, 83, 139-146(2004).

16. S. Ang, A. C. Inkpen. Dec. Sci., 39, 337-358(2008).

17. P. C. Earley, S. Ang. Palo Alto, CA: Stanford University Press (2003).

18. D. J. Teece. Strat. Man. J., 28(13), 1319-1350(2007).

19. M. W. Cohen, D. A. Levinthal. Adm. Sci. Quartrly., 35, 128-152(1990).

20. S. A. Zahra, G. George. Acdmy. of Man. Rev., 27, 185-203(2002).

21. P. J. Lane, J. E. Salk, M. A. Lyles. Strat. Man. J., 22, 1139-1161 (2001).

22. H. W. Volberda, N. J. Foss, M. A. Lyles. Strat.Man.\&Glob.,978-87-91815-51-5 (2009).

23. W. Tsai. Acdmy. of Man. J., 44(5), 996-1004(2001).

24. M. W. Lipsey, D. B. Wilson. Thousand Oaks, CA: Sage(2001)

25. Permatasari, Yani. http://ir.lib.pccu.edu.tw/bitstream/987654321/24688/2/fb14120517 4750.pdf. (2011) 


\begin{tabular}{|c|c|c|c|c|c|c|c|c|c|}
\hline \multirow{12}{*}{ 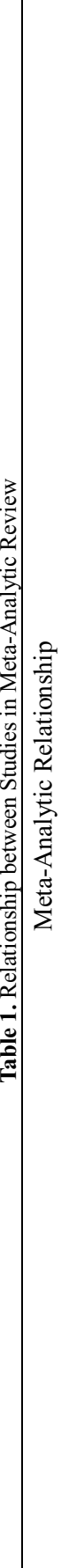 } & \multirow{4}{*}{ 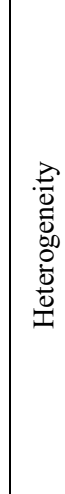 } & 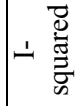 & ஜ & 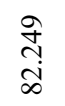 & 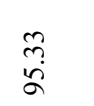 & 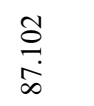 & $\frac{n}{n}$ & $\underset{\infty}{\infty}$ & $\begin{array}{l}\text { ळे } \\
\text { ふু }\end{array}$ \\
\hline & & $d \frac{\mathscr{g}}{\pi}$ & $\mid \begin{array}{l}\hat{\sigma} \\
6 \\
+\end{array}$ & $\begin{array}{l}\hat{n} \\
\infty \\
\dot{m}\end{array}$ & $\stackrel{\partial}{\dot{I}}$ & 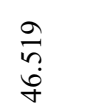 & 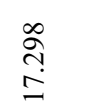 & 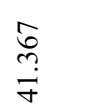 & $\begin{array}{l}\stackrel{\infty}{n} \\
\stackrel{m}{n}\end{array}$ \\
\hline & & U. & : & กิ & 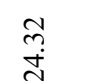 & $\stackrel{0}{\stackrel{0}{+}}$ & $\begin{array}{l}\text { 巳 } \\
\stackrel{1}{~}\end{array}$ & 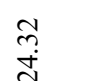 & $\begin{array}{l}\infty \\
\stackrel{\infty}{\sim} \\
\stackrel{\sim}{\sim}\end{array}$ \\
\hline & & 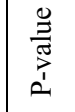 & 年 & $\begin{array}{l}8 \\
\vdots \\
0\end{array}$ & $\begin{array}{l}8 \\
0 \\
0\end{array}$ & $\stackrel{8}{8}$ & $\stackrel{8}{8}$ & $\begin{array}{l}8 \\
8 \\
0\end{array}$ & $\begin{array}{l}8 \\
8 \\
0\end{array}$ \\
\hline & \multirow{3}{*}{ 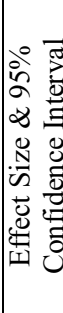 } & $\vec{\mho}$ & 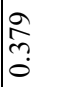 & $\frac{\vec{\infty}}{\overrightarrow{0}}$ & $\begin{array}{l}\infty \\
\tilde{\sigma} \\
0\end{array}$ & $\hat{o}$ & ڤે & $\frac{\tilde{\sigma}}{0}$ & $\frac{\infty}{m}$ \\
\hline & & త્త & $\frac{m}{\stackrel{2}{0}}$ & $\begin{array}{l}0 \\
\tilde{\delta} \\
0 \\
0\end{array}$ & $\begin{array}{l}\overrightarrow{8} \\
\dot{i}\end{array}$ & 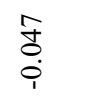 & $\frac{O}{+}$ & $\begin{array}{l}\widehat{\widehat{o}} \\
\stackrel{0}{0}\end{array}$ & సิ \\
\hline & & - & 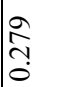 & $\begin{array}{l}\stackrel{8}{0} \\
0 \\
0\end{array}$ & $\stackrel{\infty}{\circ}$ & â & 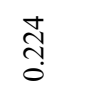 & $\begin{array}{l}\infty \\
\stackrel{0}{0} \\
0\end{array}$ & 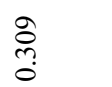 \\
\hline & \multicolumn{2}{|c|}{$\stackrel{\vec{\sigma}}{0}=$} & 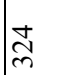 & $\stackrel{2}{2}$ & $\overrightarrow{8}$ & $\sqrt{n}$ & $\stackrel{\infty}{0}$ & ळু & $\stackrel{0}{\stackrel{2}{2}}$ \\
\hline & \multicolumn{2}{|c|}{ 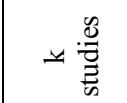 } & 0 & 0 & $\infty$ & $r$ & $r$ & $\infty$ & $\stackrel{\sim}{\sim}$ \\
\hline & \multirow[t]{2}{*}{$\frac{0}{\frac{0}{0}}$} & $\begin{array}{l}\overrightarrow{0} \\
\overline{0} \\
\bar{D} \\
\stackrel{0}{0} \\
0\end{array}$ & 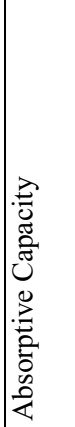 & 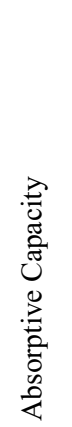 & 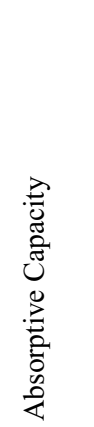 & 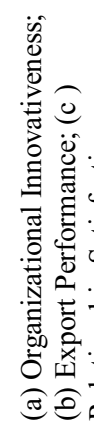 & 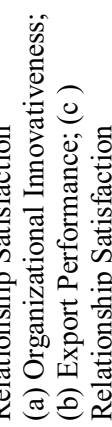 & 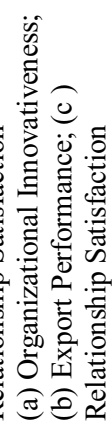 & 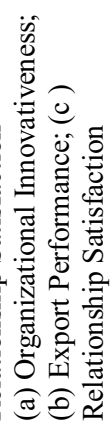 \\
\hline & & $\begin{array}{l}\overrightarrow{0} \\
\overline{0} \\
\bar{\Xi} \\
\frac{0}{0} \\
\vec{\Xi} \\
\Xi\end{array}$ & 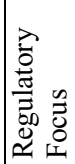 & 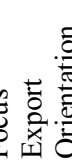 & 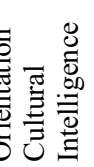 & 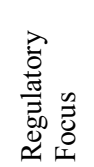 & 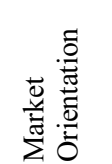 & 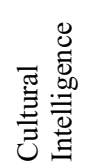 & 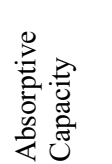 \\
\hline & \multicolumn{2}{|c|}{ 胥 } & - & $N$ & $m$ & + & $n$ & 0 & $r$ \\
\hline
\end{tabular}

